\title{
Archives of the El Niño-Southern Oscillation: A coral point of view
}

\author{
Allison E. Lawman ${ }^{1,2}$, J.W. Partin² and S.G. Dee ${ }^{1}$
}

\section{Proxy system models provide a tool to link paleoclimate proxy data with instrumental observations or climate model output. Recent advances in coral proxy system modeling cement the fidelity of tropical Pacific corals in recording changes in El Niño-Southern Oscillation variability.}

\section{Reconstructing ENSO variability using corals}

The El Niño-Southern Oscillation (ENSO) is a tropical climate phenomenon that has global impacts on temperature and rainfall patterns. Given its role as the leading mode of interannual variability and the socioeconomic impacts associated with these events, it is of paramount importance to understand how ENSO may change in the future with anthropogenic warming. Tropical climate variability is a source of notable uncertainty in future climate projections (Bellenger et al. 2014; Collins et al. 2010). While simulations provide insight into how ENSO may behave in a warmer world, they often lack critical constraints from physics (Collins et al. 2013), and require independent validation to assess the accuracy of a model's performance. This motivates the study of past ENSO variability during periods when Earth experienced different conditions compared to today's rapidly warming climate.

Corals are a paleoclimate archive wellsuited for studying ENSO variability, as they store decades to centuries of sub-annually resolved proxy climate information from the tropics (Fairbanks et al. 1997; Lough 2010). Modern corals serve to calibrate proxies with the instrumental record, while fossil corals provide snapshots of interannual variability during pre-industrial times. In particular, the ratio of strontium to calcium ( $\mathrm{S} / \mathrm{Ca}$ ) and the oxygen isotopic composition $\left(\delta^{18} \mathrm{O}\right)$ of the coral skeleton are well-established proxies for oceanic conditions. Coral Sr/Ca varies in response to changes in sea-surface temperature (SST), while coral $\delta^{18} \mathrm{O}$ jointly records changes in SST and the ratio of the oxygen isotopic composition of seawater to salinity $\left(\delta^{18} \mathrm{O}\right.$, /salinity; Corrège 2006; Lough 2010).

\section{Proxy system modeling as a tool to quantify uncertainties}

On interannual timescales, corals from the tropical Pacific are influenced by ENSO, local variability, and how the coral itself records climate information. Since corals are widely used to reconstruct paleo-ENSO variability, it is critical to quantify how these factors impact estimates of interannual variability in proxy records. A proxy system model (PSM) is a tool that quantifies sources of uncertainty by mathematically modeling how different processes impact a climate signal that emerges from the proxy data (Dee et al. 2015; Evans et al. 2013). Paleoclimate proxy data is often used to reconstruct climate variables, such as temperature, via empirically determined calibration equations. Alternatively, a PSM can use observed or simulated climate information and generate a forward-modeled time series of what a hypothetical proxy under those conditions would record, i.e. a "pseudoproxy". This calculation translates the climate signal to a proxy signal and considers ways by which the proxy alters the input signal. PSMs thus provide a means to directly compare proxy data and instrumental observations or climate model output in the same units.

Coral proxy system modeling work by Thompson et al. (2011) provides an example of a transfer function used to forward model "pseudocoral" $\delta^{18} \mathrm{O}$ as a linear combination of SST and $\delta^{18} \mathrm{O}_{\text {seawater }}$ /salinity. This sensor model has since been used for many purposes, including comparing coral $\delta^{18} \mathrm{O}$ records with pseudocoral time series generated from instrumental observations and historical climate model simulations (Thompson et al. 2011), and quantifying errors in coral-inferred estimates of ENSO amplitude (Russon et al. 2015) and variability
(Stevenson et al. 2013). Our recent coral PSM builds on this and earlier studies by adding new features, called sub-models, into an existing coral PSM framework (Lawman et al. 2020). We use temperature and salinity output from the Community Earth System Model Last Millennium Ensemble (CESMLME; Otto-Bliesner et al. 2016) to model pseudocoral $\delta^{18} \mathrm{O}$ and SST derived from coral $\mathrm{Sr} / \mathrm{Ca}\left(\mathrm{SST}_{\mathrm{Sr} / \mathrm{C}}\right.$ ) and quantify how uncertainties associated with assumptions about (1) analytical and proxy-calibration errors, (2) variable coral growth rates, and (3) coral age-depth modeling impact estimates of interannual variability, here defined at the standard deviation of $\delta^{18} \mathrm{O}$ and $\mathrm{SST}_{\mathrm{Sr} / \mathrm{C}}$ anomalies.

Our results demonstrate that calibration and analytical errors increase estimates of interannual variability in coral geochemical records, whereas variations in growth rates, when combined with certain age modeling assumptions, systematically decrease estimates of interannual variability. When all three sub-models are coupled, we find that such factors can measurably change the standard deviation of $\delta^{18} \mathrm{O}$ and $\mathrm{SST}_{\mathrm{Sr} / \mathrm{C}}$ anomalies on the order of $10-30 \%$ compared to the original, and that the relative importance of each sub-model is specific to individual sites (Fig. 1). We attribute the degree of site-specific changes in interannual variability to the tradeoff between the strength of the interannual signal (ENSO) and the amplitude of the SST annual cycle at a given site.

The PSM is a useful tool for not only quantify ing how various coral uncertainties manifest locally at individual sites, but also how they impact a coral's ability to broadly capture changes in ENSO variability. The Niño 3.4

\section{A. $\mathrm{SST}_{\mathrm{Sr} / \mathrm{Ca}}$}

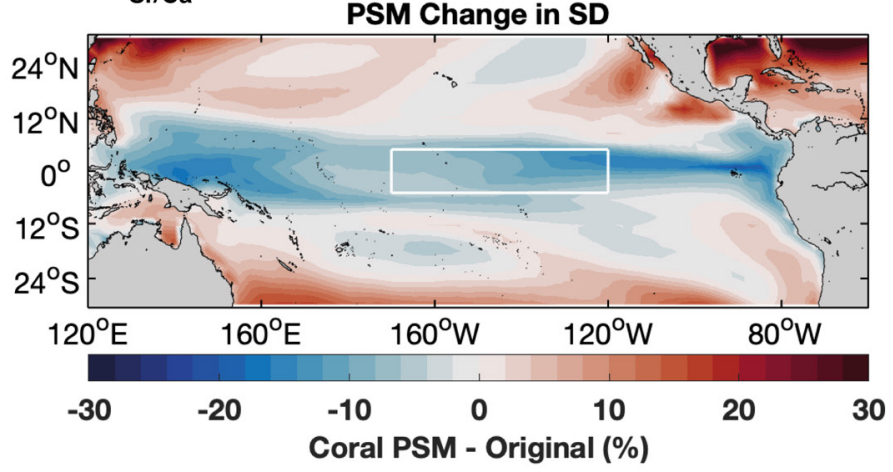

B. $\delta^{18} \mathrm{O}$

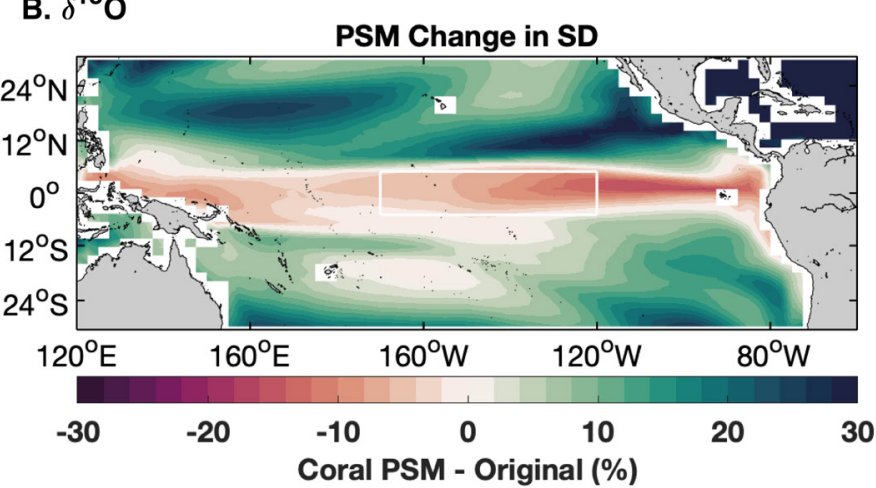

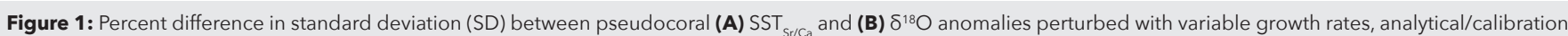
errors, and the age modeling algorithm ( $n=100$ realizations), and the original, unperturbed environmental input. The white box outlines the Niño 3.4 region. The model output used here and in Figure 2 is from the CESM-LME 850 control simulation (Otto-Bliesner et al. 2016). Figure reproduced with permission from Lawman et al. (2020). 
SST anomalies

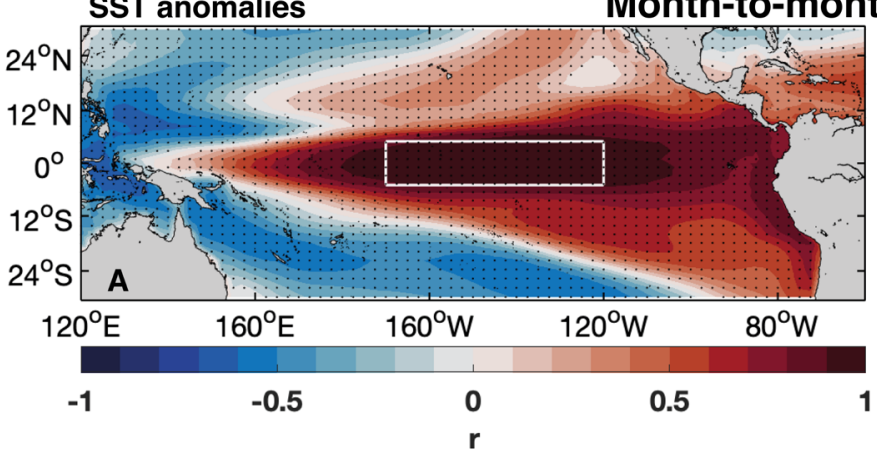

ENSO variability

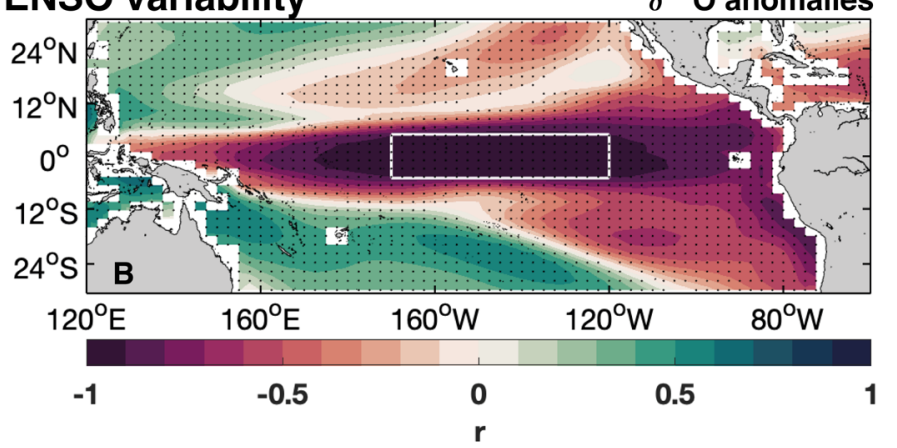

Decadal+ ENSO variability
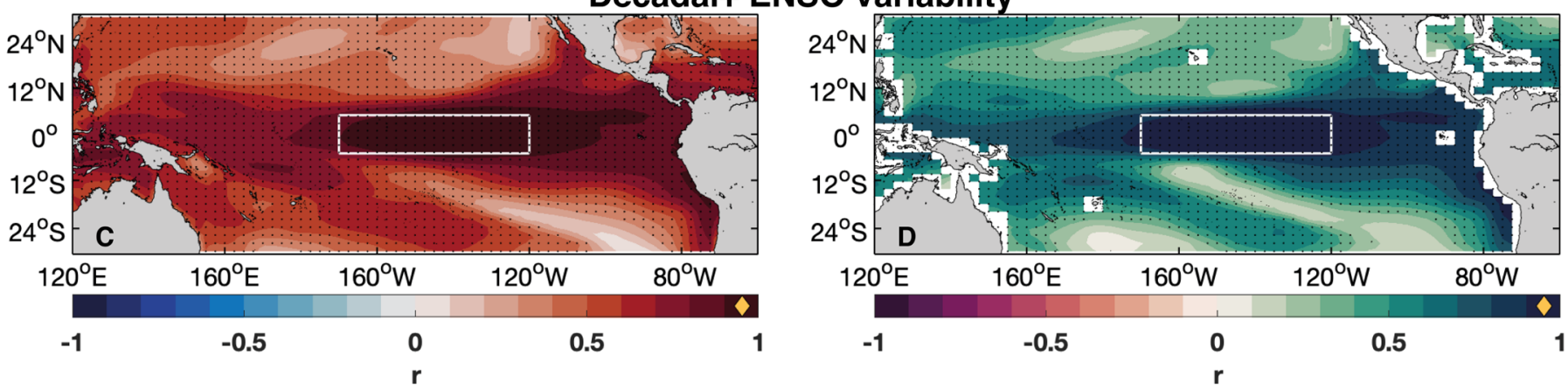

Decadal+ ENSO variability with coral PSM sub-models
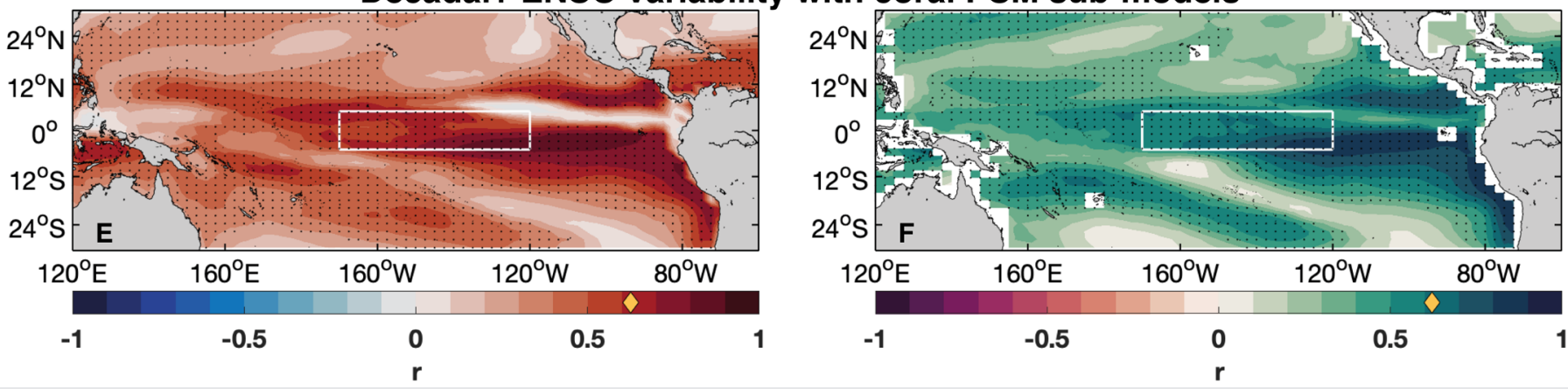

Figure 2: Correlation between Niño 3.4 SST anomalies and values at each grid point. Monthly Niño 3.4 SST anomalies correlated with monthly (A) SST anomalies and (B) $\delta^{18} \mathrm{O}$ generated using the sensor model of Thompson et al. (2011). The 20-year running SD of Niño 3.4 SST anomalies (i.e. decadal+ changes in ENSO variability) correlated with

(C) SST and (D) pseudocoral $\delta^{18} \mathrm{O}$ anomalies. The 20 -year running SD of Niño 3.4 SST anomalies correlated with (E) SST Sr/Ca $_{\text {and }}$ (F) pseudocoral $\delta^{18} \mathrm{O}$ anomalies perturbed by the three coral PSM sub-models. Statistically significant correlations $(p<0.01)$ are stippled. The gold diamond (C-F) indicates the average correlation coefficient for the Niño

3.4 region (white box). Figure reproduced with permission from Lawman et al. (2020).

region has been identified as a "center of action" for ENSO (Fig. 2a-b), and the monthto-month correlation between SST and SST anomalies over this region is a common metric for assessing the ENSO sensitivity at a site. However, fossil corals with absolute age errors on the order of $1 \%$ preclude such a precise month-to-month reconstruction back in time. To address this limitation, we investigate how local $\delta^{18} \mathrm{O}$ and $\mathrm{SST}_{\mathrm{Sr} / \mathrm{Ca}}$ variability track changes in ENSO variability on decadal and greater timescales (decadal+) using the correlation between the running standard deviation of pseudocoral $\delta^{18} \mathrm{O}$ and $\mathrm{SST}_{\mathrm{Sr} / \mathrm{Ca}}$ anomalies with Niño 3.4 SST anomalies (Fig. 2c-d). Although the correlations are, as expected, smaller (Fig. 2e-f) than the original inputs not processed with the three PSM sub-models, the temporal relationship between changes in the pseudocorals and changes in Niño 3.4 SST variability is broadly preserved. Many circum-Pacific locations, particularly those near coral atolls, demonstrate statistically significant correlations with ENSO changes. This highlights the ability of corals from across the tropical Pacific to capture decadal+ changes in ENSO variability.

\section{Future perspectives}

Although different processes and assumptions inherent to paleoclimate studies may impact estimates of interannual variability recorded by corals, our recent PSM work highlights the strength of corals in their ability to capture decadal+ changes in ENSO variability. It is most appropriate to compare coral geochemical data with instrumental or climate model output processed through a PSM, as it places the two types of data on a more level playing field. To help facilitate such comparisons, our new PSM sub-models are publicly available to the climate community via a GitHub repository (https:// github.com/lawmana/coralPSM). Future work comparing coral geochemical data with climate model observations translated to coral units using a process-based PSM will be a key step toward reconciling differences between models and coral geochemical observations. It is our hope that sharpening our data-model comparisons for the tropical oceans will allow us to refine the implementation of important physical processes in models, thereby reducing uncertainties in future ENSO projections.

\section{AFFILIATIONS}

'Department of Earth, Environmental and Planetary Sciences, Rice University, Houston, TX, USA ${ }^{2}$ Institute for Geophysics, The University of Texas at Austin, USA

\section{CONTACT}

Allison E. Lawman: Allison.Lawman@rice.edu

\section{REFERENCES}

Bellenger H et al. (2014) Clim Dyn 42: 1999-2018

Collins M et al. (2010) Nat Geosci 3: 391-397

Collins M et al. (2013) In: Stocker TF et al. (Eds) Climate Change 2013: The Physical Science Basis.

Cambridge University Press, 1029-1136

Corrège T (2006) Palaeogeogr Palaeoclimatol Palaeoecol 232: 408-428

Dee S et al. (2015) J Adv Model Earth Syst 7: 1220-1247

Evans MN et al. (2013) Quat Sci Rev 76: 16-28

Fairbanks RG et al. (1997) Coral Reefs 16: S93-S100

Lawman AE et al. (2020) Paleoceanogr Paleoclimatol 35: e2019PA003836

Lough JM (2010) WIREs Clim Change 1: 318-331

Otto-Bliesner BL et al. (2016) Bull Am Meteorol Soc 97: 735-754

Russon T et al. (2015) Geophys Res Lett 42: 1197-1204 Stevenson S et al. (2013) Paleoceanography 28: 633-649 Thompson DM et al. (2011) Geophys Res Lett 38: L14706 